\title{
A new approach for planning M.C.W.H. systems with annual rainfall-runoff data
}

\author{
S. Giakoumakis ${ }^{1}$, A. Skalieris
}

Laboratory of Reclamation Works and Water Resources Management, School of Rural and Surveying Eng., NTUA, 9 Iroon Polytechniou Str., 15780, Athens, Greece. sgiakou@central.ntua.gr

\begin{abstract}
In the present study a new approach for planning Micro-Catchment Water Harvesting (M.C.W.H.) systems for irrigation in semi-arid regions such as the Aegean islands, is presented. This is a cheap solution for constructing infrastructure with zero energy cost in regions where water is scarce. The proposed approach introduces simple linear relationships for estimating the annual volume of water $V_{s}$ collected mainly from the CA (Contributing Area), stored in the root zone (Infiltration Basin, IB), according to the annual rainfall and runoff depths, after having determined the ratio of areas of micro-catchment components i.e. $\lambda=\mathrm{ACA}_{\mathrm{CA}} \mathrm{A}_{\mathrm{IB}}$ and its whole area $\mathrm{AMC}_{\mathrm{MC}}$ This procedure was applied in Paros island of the Cyclades complex in the middle of the Aegean sea in east Mediterranean. Besides, income-cost analysis was performed via NPV method for almonds, peach and apricot trees.
\end{abstract}

Keywords: M.C.W.H., semi-arid regions, rainfall, runoff, $\mathrm{V}_{\mathrm{s}}, \lambda$, AMC.

\section{Introduction}

In many regions of southern Europe (e.g. in most east Mediterranean islands), water is not enough for intensive irrigation development. In some other cases, due to various technical and economic reasons, water cannot be transferred over long distances. As a result, large areas remain without irrigation water and therefore, they are solely dependent on rainfall (Tsakiris 1991). In order to increase the availability of water for crop production, several types of Rain Water Harvesting techniques (RWH) such as Micro-Catchment Water Harvesting (M.C.W.H.), which is a method for inducing, collecting, storing and conserving local surface runoff for agriculture in arid and semi-arid regions, is adopted (Boers and Ben-Asher 1982, Giakoumakis 2008). M.C.W.H. is a likely viable option to increase water productivity at the production system level. M.C.W.H. and similar techniques have a significant potential for improving and sustaining the rainfed agriculture in the region of application.

${ }^{1}$ Corresponding author 
M.C.W.H. is not a recent discovery. Throughout history, archaeological evidence has revealed M.C.W.H. sites that were implemented in arid environments (annual rainfall less than $200 \mathrm{~mm}$ ) such as Jordan, the Negev desert in Israel (Holy Land), Syria, Tunisia and Iraq. The earliest signs of M.C.W.H. are believed to have been constructed over 9000 years ago in the Edom Mountains in southern Jordan (Adham et.al. 2016).

Low rainfall, water scarcity and land degradation severely intimidate the production capacities of the rangelands in the arid environments. Surface crusting by raindrops helps generating frequent local runoff on degraded sloping land, but it is generally lost in transmission and seldom flows down to streams. Micro-catchments can capture local runoff, reduce transmission losses and concentrate it into the plant basins. Thus, an efficient water harvesting planning is necessary for increasin the runoff production potential of micro-catchments and water storage capacity of the soil in the plant basins (Ali et al., 2007).

The purpose of the present paper is to assess the effectiveness of M.C.W.H. technique in Paros island of Cyclades in the middle of the Aegean sea, in a semi-arid environment, proposing a simple and versatile approach for planning a low cost M.C.W.H. system, based on annual rainfall and runoff data. This approach can also be used without any changes, in arid environments.

\section{Theory}

For determining design criteria in a M.C.W.H. system, the following was considered:

1. Based on measured annual rainfall data, design rainfall for a given return period (i.e. $\mathrm{T}=8$ years, FAO 1991) is derived.

2. From the design rainfall, annual runoff is calculated via SCS-CN model.

3. The annual water balance in the IB (Infiltration Basin) is a valid hypothesis, taking into account that rainfall in semi-arid regions occurs mainly during the wet period of a hydrologic year (from October to April) and almost not at all during the dry period.

A micro-catchment is composed from the Contributing Area (CA) where runoff occurs and the Infiltration Basin (IB) where water is stored directly in the root zone for crop requirements (Fig. 1). 


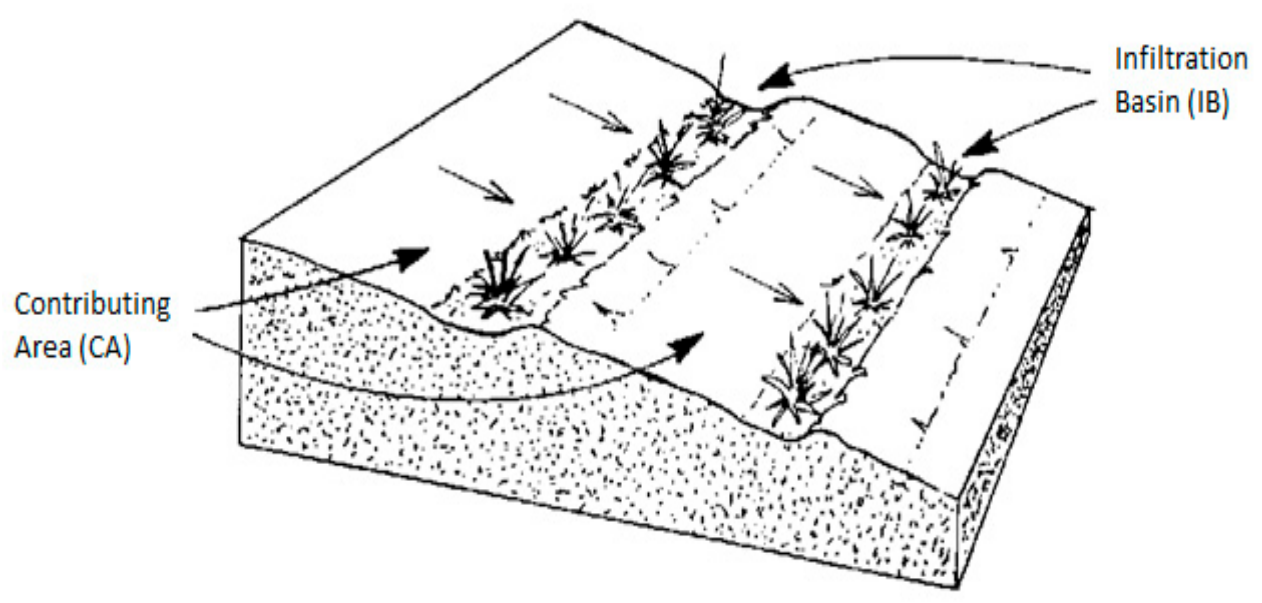

Figure 1. Typical micro-catchment and its components (strip form IB)

The annual runoff volume from $\mathrm{CA}$ to $\mathrm{IB}\left(\mathrm{m}^{3}\right)$ is given by:

$\mathrm{V}_{\mathrm{CA}}=0.001 \cdot \mathrm{R} \cdot \mathrm{A}_{\mathrm{CA}}$

where:

R: runoff from CA (Contributing Area), (mm)

$\mathrm{A}_{\mathrm{CA}}$ : area of CA $\left(\mathrm{m}^{2}\right)$

The annual volume of water from rainfall $\mathrm{P}$ in the IB is:

$\mathrm{V}_{\mathrm{IB}}=0.001 \cdot \mathrm{P} \cdot \mathrm{A}_{\mathrm{IB}}$

where:

$\mathrm{P}:$ annual rainfall, $(\mathrm{mm})$

AIB: area of IB $\left(\mathrm{m}^{2}\right)$

If it is supposed that $\mathrm{p}$ is the percentage of volume of water infiltrating into IB and lost as deep percolation losses or/and evaporation from soil surface, the water volume finally stored in the IB is:

$\mathrm{V}_{\mathrm{s}}=(1-\mathrm{p}) \cdot\left(\mathrm{V}_{\mathrm{CA}}+\mathrm{V}_{\mathrm{IB}}\right)$

However, the annual volume necessary for crop water requirements in the IB is given by:

$\mathrm{V}_{\mathrm{RE}}=0.001 \cdot \mathrm{ET}_{\mathrm{c}} \cdot \mathrm{A}_{\mathrm{IB}}$

where: 
$\mathrm{ET}_{\mathrm{c}}$ : potential evapotranspiration of the crop $(\mathrm{mm})$.

Thus, for an effective planning it should be $V_{s}=V_{R E}$ Taking into account eqns 1, 2, 3 and 4, one obtains:

$\mathrm{A}_{\mathrm{CA}} / \mathrm{A}_{\mathrm{IB}}=\left[\mathrm{ET}_{\mathrm{c}}-\mathrm{P} \cdot(1-\mathrm{p})\right] /[(1-\mathrm{p}) \cdot \mathrm{R}]$

From eqn 5 the ratio $\lambda=\mathrm{ACA}_{\mathrm{CA}} / \mathrm{A}_{\mathrm{IB}}$ of areas of CA and IB can be calculated.

If $\mathrm{AMC}_{\mathrm{MC}}$ is the total micro-catchment area in $\mathrm{m}^{2}$, then:

$\mathrm{AMC}_{\mathrm{MC}}=\mathrm{ACA}+\mathrm{AIB}$

Taking into account that $\lambda=\mathrm{A}_{\mathrm{CA}} / \mathrm{A}_{\mathrm{IB}}$ and eqn $6, \mathrm{~A}_{\mathrm{CA}}$ and $\mathrm{A}_{\mathrm{IB}}$ can be expressed as follows:

$\mathrm{A}_{\mathrm{CA}}=\mathrm{A}_{\mathrm{MC}} \cdot[\lambda /(1+\lambda)]$

and

$\mathrm{A}_{\mathrm{IB}}=\mathrm{A}_{\mathrm{MC}} \cdot[1 /(1+\lambda)]$

Combining eqns $1,2,3,7$ and 8 , yields:

$\mathrm{V}_{\mathrm{s}}=0.001 \cdot \mathrm{AMC}_{\mathrm{MC}} \cdot(\mathrm{P}+\mathrm{R} \cdot \lambda) \cdot[(1-\mathrm{p}) /(1+\lambda)]$

Eqn 9 can be viewed as a key-relationship, expressing the annual volume of water stored in the IB $\left(\mathrm{m}^{3}\right)$ as a linear function of the total $\mathrm{MC}$ area, $\mathrm{AmC}\left(\mathrm{m}^{2}\right)$, with parameter $\lambda$ being calculated from eqn 5 for given annual rainfall and runoff depths, $P$ and $\mathrm{R}(\mathrm{mm})$, respectively.

\section{Case study}

The above was applied in Paros island in the middle of the Aegean sea (latitude $37^{\circ}$ $5^{\prime}$, longitude $25^{\circ} 14^{\prime}$ ), (Fig. 2). Although climatologicl conditions are appropriate for applying the M.C.W.H. technique for irrigation, agricultural areas of the island are fed by drillings, leading to the lowering of underground water level, increasing so the risk of salt water intrusion. 


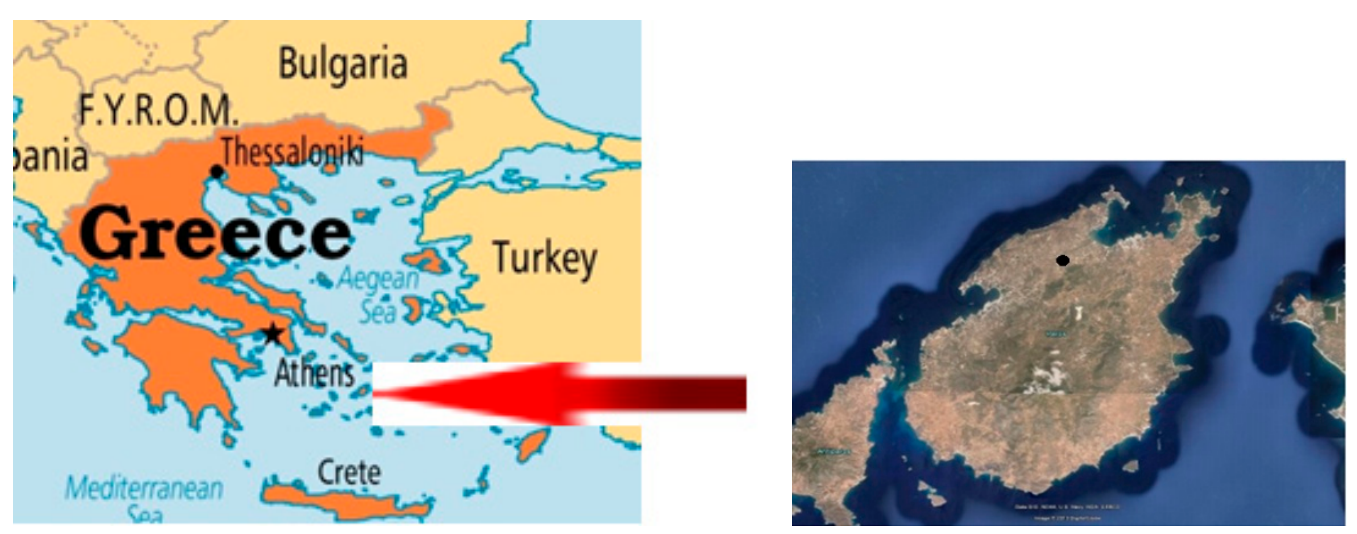

Figure 2. Paros island and selected (dot) region's location for M.C.W.H application

So, it was decided to select a region as a pilot one in order to prove that M.C.W.H. technique may resolve with low cost the irrigation problem of the island and save so invaluable underground water resources for other uses (i.e. drinking water after treatment). The region selected has an area of 7 ha $(200 \times 350 \mathrm{~m})$. Its position (in the north of the island, near Longovardas monastery) is illustrated in Figure 2. It is ideal because all of the criteria for the installation of a M.C.W.H. system are fulfilled (Rands 1980). Namely:

$\begin{array}{ll}\text { 1. } & \text { Soil slope between } 2 \text { and } 8 \% \\ \text { 2. } & \text { Medium soil texture } \\ \text { 3. } & \text { Soil depth greater than } 1.5 \mathrm{~m} \\ \text { 4. } & \text { Not cultivated land } \\ \text { 5. } & \text { Area of a few ha }\end{array}$

From the categories of M.C.W.H., the strip farming was selected because it is easily constructed and well adapted in an inclined surface like the chosen one.

From the local station of National Meteorological Service having the same altitude as the mean one of the selected area (i.e. $32 \mathrm{~m}$ a.s.l), a time series of annual rainfall date was used for the last 30 years. It was shown via $\mathrm{x}^{2}$ test that these data are well adapted to a normal distribution with mean value $\mathrm{P}_{\mathrm{m}}=560.8 \mathrm{~mm}$ and standard deviation $\mathrm{s}=171.5 \mathrm{~mm}$. The well-known frequency factor relationship was used for determining design rainfall depth, which, for a normal distribution is written as:

$\mathrm{P}_{\mathrm{T}}=\mathrm{P}_{\mathrm{m}}+\mathrm{s} \cdot \mathrm{z}$

Where $\mathrm{P}_{\mathrm{T}}$ is the design rainfall depth $(\mathrm{mm})$ for return period $\mathrm{T}$ and $\mathrm{z}$ is the variable of the unit normal distribution:

$\mathrm{Z}=\left(\mathrm{P}-\mathrm{P}_{\mathrm{m}}\right) / \mathrm{s}$ 
According to FAO (1991) a return period of 8 years was chosen. This corresponds to an exceedance probability of 0.125 and thus $z=-1.15$. From eqn 10 one obtains $\mathrm{P}_{\mathrm{T}=8}=363.5 \mathrm{~mm}$.

Using then SCS-CN model for initial losses $20 \%$ of the total (SCS 2004) with CN=94 (Wanielista 1990) for a bare soil surface in the CA having previously been treated in order to minimize soil infiltrability (category D), the corresponding total losses $\mathrm{S}$ were calculated as equal as $16.2 \mathrm{~mm}$ and annual design runoff depth $\mathrm{R}$ was then derived as equal as $344.7 \mathrm{~mm}$. The following relations have been used:

$\mathrm{R}=(\mathrm{P}-0.2 \cdot \mathrm{S})^{2} /(\mathrm{P}+0.8 \cdot \mathrm{S})$ for $\mathrm{P}>0.2 \cdot \mathrm{S}$

$\mathrm{R}=0$ for $\mathrm{P} \leq 0.2 \cdot \mathrm{S}$

where:

P: rainfall depth $(\mathrm{mm})$

$\mathrm{R}$ : runoff depth (mm)

S: total losses (mm) given by (SI units): $\mathrm{S}=(25400 / \mathrm{CN})-254$

Reference potential evapotranspiration was calculated via Thornthwaite formula because that only mean monthly temperature and sunshine duration data were available from the nearby meteorological station, that is the unique in the island. Monthly crop coefficients from April to October for the arboricultures selected (i.e. almonds, peach and apricot tress) were found in the literature (Kougkolos 2017). The annual values of crop evapotranspiration were as equal as $\mathrm{ET}_{\mathrm{c}}=432.4 \mathrm{~mm}$ for almonds trees, whereas $\mathrm{ET}_{\mathrm{c}}=603.7 \mathrm{~mm}$ for peach and apricot trees.

Substituting the corresponding values of $\mathrm{ET}_{\mathrm{c}}, \mathrm{P}$ and $\mathrm{R}$ in eqn 5 with $\mathrm{p}=0.3$, which sounds logical for medium texture soils, the $\lambda$ ratio for the MCs is:

$\lambda=\mathrm{A}_{\mathrm{CA}} / \mathrm{A}_{\mathrm{IB}}=0.7$ for almonds trees and $\lambda=\mathrm{A}_{\mathrm{CA}} / \mathrm{A}_{\mathrm{IB}}=1.5$ for peach and apricot trees.

Thus, from eqn 9 one obtains:

$\mathrm{V}_{\mathrm{s}}=0.25 \cdot \mathrm{AMC}$

for almonds, peach and apricot trees. Thus, the annual volume of water $\mathrm{V}_{\mathrm{s}}$ expected to be stored in IB, equals for each kind of trees, the $25 \%$ of the total MC area.

Taking into account that for almonds trees the root zone for each tree is of minimum diameter $2.3 \mathrm{~m}$ and that distance between trees should not be less than $4 \mathrm{~m}$ (Kougkolos 2017), the proposed IB dimensions for this arboriculture are: $2.5 \mathrm{~m}$ length and $4 \mathrm{~m}$ width, or $A_{I B}=10 \mathrm{~m}^{2}$. With computed $\lambda=A_{C A} / A_{I B}=0.7$, the area of the $C A$ should be $7 \mathrm{~m}^{2}$ with the same width as previously (i.e. $4 \times 1.75 \mathrm{~m}$ ). So, each MC in total will be $17 \mathrm{~m}^{2}$. According to eqn 13, the expected annual stored volume of 
rainwater per IB for crop water requirements can reach $4.25 \mathrm{~m}^{3}$.

Besides, taking into account that for peach and apricot trees the root zone for each tree is of minimum diameter $1.8 \mathrm{~m}$ and that distance between trees should not be less than $3 \mathrm{~m}$ (Kougkolos 2017), the proposed IB dimensions for this arboriculture are: $2 \mathrm{~m}$ length and $3 \mathrm{~m}$ width, or $A_{I B}=6 \mathrm{~m}^{2}$. With computed $\lambda=A_{C A} / A_{I B}=1.5$, the area of the CA should be $9 \mathrm{~m}^{2}$ with the same width as previously (i.e. $3 \times 3 \mathrm{~m}$ ). So, each MC in total will be $15 \mathrm{~m}^{2}$. According to eqn 13, the expected annual stored volume of rainwater per IB for crop water requirements can reach in this case $3.75 \mathrm{~m}^{3}$.

MC's dimensions are illustrated in Figures $3 \mathrm{a}$ and $3 \mathrm{~b}$ for almonds and peach-apricot trees, respectively.

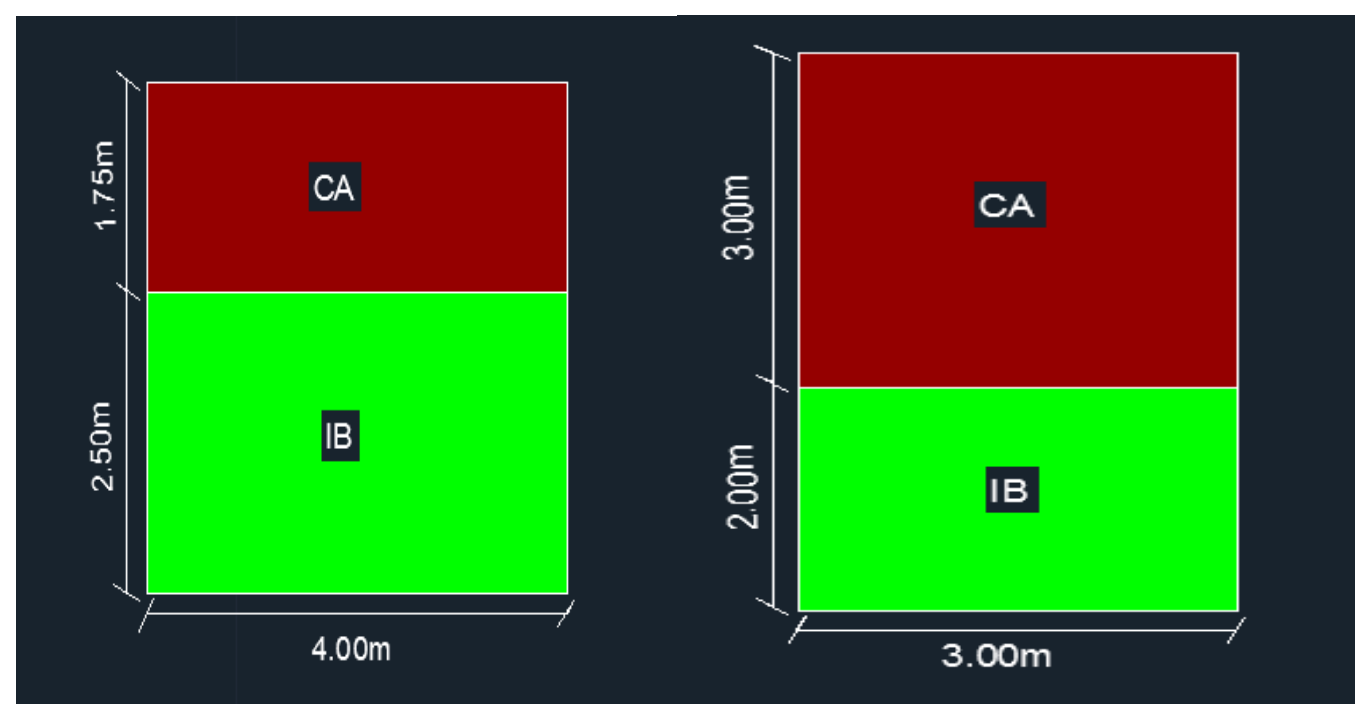

a)

b).

Figure 3. MC for: a). Almonds trees b). Peach and apricot trees

A rural road network will be constructed in the total area of 7 ha and so, the net irrigated will be of 6.6 ha or 2.2 ha per arboriculture. Thus, $22000 / 17=1294$ almonds trees will be planted, also 22000/15=1467 peach trees and 1467 apricot trees (Fig.4). 


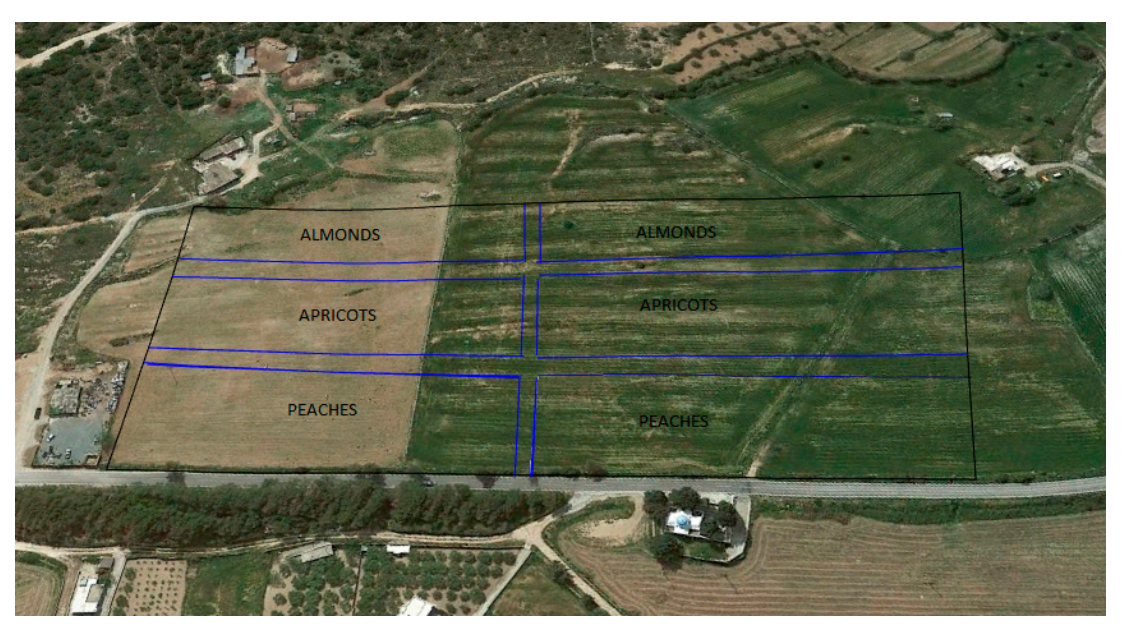

Figure 4. Region of application

Economic evaluation of the application of the M.C.W.H. technique was performed by the well-known NPV method:

$\operatorname{NPV}(i, N)=\sum_{t=0}^{N} \frac{R_{t}}{(1+i)^{t}}$

where

$t$ the time of the cash flow

$i$ the discount rate

$\mathrm{N}$ the total number of periods

$\mathrm{R}_{\mathrm{t}}$ the net cash flow i.e. cash inflow - cash outflow, at time $t$.

In our case it was taken $\mathrm{N}=8$ as the return period of the annual rainfall, and $\mathrm{i}=10 \%$ (mean value for reclamation works in Greece).

The cost of construction is given in the following Table:

Table1. Cost of construction (euro)

\begin{tabular}{|l|l|}
\hline Earthworks + CAs surface treatment & 21000 \\
\hline Trees purchase and plantation & $85000(*)$ \\
\hline SUM & 106000 \\
\hline
\end{tabular}

(*) All kind of trees will be three year old for giving fruits immediately (Pontikis 1997).

It's estimated that total annual cost for fertilizers, pesticides and pruning for 4228 trees is 10000 euro.

For almonds trees the mean annual production is $10 \mathrm{~kg} / \mathrm{year} /$ tree with selling price from the producer 6 euro/ $\mathrm{kg}$ (Nanos 2018). For peach trees $40 \mathrm{~kg} / \mathrm{year} / \mathrm{tree}$ with 0.3 
euro/ $\mathrm{kg}$ and for apricot trees $35 \mathrm{~kg} /$ year/tree with also 0.3 euro/ $\mathrm{kg}$ (Tavoularis 2012). Thus, the annual income for the producer is given in the following Table:

Table 2. Annual income (euro)

\begin{tabular}{|l|l|}
\hline Almonds trees & $6.0 \cdot 10 \cdot 1294=77640$ \\
\hline Peach trees & $0.3 \cdot 40 \cdot 1467=17604$ \\
\hline Apricot trees & $0.3 \cdot 35 \cdot 1467=15404$ \\
\hline SUM & 110648 \\
\hline
\end{tabular}

Then, eqn 14 was applied. Results are presented in Table 3.

Table 3. NPV's calculation (euro)

\begin{tabular}{|l|l|l|l|l|}
\hline YEAR & Cash outflow & Cash inflow & R & NPV \\
\hline 0 & 106000 & 0 & -106000 & -106000 \\
\hline 1 & 10000 & 110648 & 100648 & 91498 \\
\hline 2 & 10000 & 110648 & 100648 & 83180 \\
\hline 3 & 10000 & 110648 & 100648 & 75618 \\
\hline 4 & 10000 & 110648 & 100648 & 68744 \\
\hline 5 & 10000 & 110648 & 100648 & 62494 \\
\hline 6 & 10000 & 110648 & 100648 & 56813 \\
\hline 7 & 10000 & 110648 & 100648 & 51648 \\
\hline 8 & 10000 & 110648 & 100648 & 46953 \\
\hline SUM & & & & $\mathbf{4 3 0 9 4 8}>\mathbf{0}$ \\
\hline
\end{tabular}

From Table 3 one concludes that the investment is advantageous.

\section{Conclusions}

In the present study a new approach for planning micro-catchments for the M.C.W.H. technique is proposed. After having determined the ratio $\lambda$ of the areas of the components of each micro-catchment, the water volume expected to be stored in the root zone of each IB, can be estimated. The relevant relationships derived are of linear form and easily applied, provided that annual design rainfall and runoff are known.

The new approach was applied in a region of Paros island of the Aegean sea with semi-arid climatic conditions and it was proved via NPV's calculation, that M.C.W.H. technique as irrigation method exploiting natural rainfall, is advantageous for the island. 


\section{References}

Adham A., Riksen M., Quessar M. and Ritsema C.J., 2016. A Methodology to Assess and Evaluate Rainwater Harvesting Techniques in (Semi-) Arid Regions, Water. 8(5), 198.

Ali A., Rashid M., El-Naggar S. and Aal A. 2007. Water harvesting options in the drylands at different spatial scales, Land Use and Water Resources Research. 7, $1-13$

Boers T. and Ben-Asher J., 1982. A review of rainwater harvesting, Agric. Water Manage. 5, 145-158.

F.A.O., 1991. Water Harvesting (AGL/MISC/17/91), Rome, Italy.

Giakoumakis S., 2008. Rainwater harvesting in arid and semi-arid regions, Int. Symposium "Water Shortage Management" Proc., 159-165.

Kougkolos A., 2017. Environmental Engineering: Pollution and Protection of the Environment, Tziolas Pub., Thessaloniki (in greek).

Nanos G., 2018. Special arboriculture, University of Thessaly, School of Agricultural Sciences, Thessaly (in greek).

Pontikis K., 1997. General arboriculture, Stamoulis Pub., Athens (in greek).

Rands B., 1980. Double cropping in semi-arid regions using water harvesting agrosystems, Master Thesis, University of Arizona.

SCS, 2004. National Engineering Handbook, Section 4: Hydrology, Soil Conservation Service, USDA, Washington, D.C., 2004.

Tavoularis K., 2012. Average crop yields in Greece. Ministry of foods and rural development, Department of rural policy and documentation, Athens (in greek).

Tsakiris G., 1991. Micro-Catchment Water Harvesting in Semi-Arid Regions: Basic Design Considerations, Water Resour. Manage. 5, 85-92.

Wanielista M., 1990. Hydrology and Water Quantity Control. John Wiley \& Sons, New York. 